\title{
Progress in the Diagnosis and Management of Pulmonary Hypertension in Children
}

\author{
Jeremy Nicolarsen, $\mathbf{M D}^{1}$ and $\mathbf{D}$. Dunbar Ivy, $\mathbf{M D}^{1}$ \\ ${ }^{1}$ Department of Pediatrics, University of Colorado and Children's Hospital Colorado, Aurora, \\ Colorado
}

\begin{abstract}
Purpose of Review-Pulmonary hypertension $(\mathrm{PH})$ is a complex disease that extends beyond merely elevated pulmonary blood pressures and right ventricular dysfunction. Its multiple etiologies and ever-expanding diagnostic tools and therapeutic approaches make it a heterogeneous disease with widely variable clinical sequelae. There are still many unanswered questions that challenge our understanding of this disease.
\end{abstract}

Recent Findings-The study of PH in the pediatric patient is as robust as ever, with the creation and inclusion of pediatric-specific disease characteristics in the most recent World Health Organization classification system, improved understanding of the pathophysiology of PH in pediatric diseases like bronchopulmonary dysplasia, and increasingly expanding diagnostic tools and management possibilities. While the use of PH therapies in children previously often relied on expert opinion and inferences from studies involving adults, pediatric-targeted research is becoming more widely supported and pursued, and even has come under recent debate, which at the very least stimulates further collaboration and discussion.

Summary-This review will highlight the changes in the PH classification system, briefly explore PH in bronchopulmonary dysplasia, and provide updates on the diagnostic and management tools used by experts in the field.

\section{Keywords}

pulmonary hypertension; bronchopulmonary dysplasia; pediatrics; diagnosis; treatment

\section{Introduction}

Pulmonary hypertension $(\mathrm{PH})$ continues to be a significant contributor to morbidity and mortality in pediatric patients. Its broad spectrum of pathogenesis, disease manifestation, therapeutic approach, and prognosis makes it a challenging, yet rewarding, area of medicine.

Corresponding Author: Jeremy Nicolarsen, MD Children's Hospital Colorado Division of Cardiology B100 13123 E 16th Avenue Aurora, CO 80045, USA Tel.: +1 7207776820 Fax: +1 7207777290 jeremy.r.nicolarsen@ ucdenver.edu.

The inclusion of the following papers with annotations is important for the following reasons: 15 - Bhat 2012 - One of initial key studies prospectively evaluating PH in patients with BPD and identifying the need to repeat echocardiography beyond 4-6 weeks of life. Given relatively substantial discussion of BPD in our paper, we feel that highlighting the study is important. 49 - Barst 2012 Landmark study of sildenafil in pediatric patients that led to the controversial FDA warning placed on this drug, a staple of PAH treatment in pediatric patients. Significant discussion is devoted to this topic and highlighting this paper is essential. 
From fetus to adolescent, child to adult, $\mathrm{PH}$ can involve or result from genetic, cellular, and physiologic derangements of the pulmonary, cardiovascular, hepatic, hematologic, and connective tissue systems. In children, prematurity, congenital heart disease, and other diseases like bronchopulmonary dysplasia (BPD) play a particularly important role in lung development and integrity. Regardless of the cause, $\mathrm{PH}$ and pulmonary arterial hypertension (PAH), which more specifically defines abnormalities of the pre-capillary pulmonary vasculature, share at their core the untoward effects of elevated pulmonary pressures on right ventricular size, function, and overall health and mortality. This review will discuss recent advances in our understanding and management of pediatric pulmonary hypertension.

\section{Updates on the Clinical Classification of Pulmonary Hypertension}

To systematically and appropriately apply what we learn in PH, a diagnostic classification has been developed and modified at the World Symposiums on Pulmonary Hypertension (WSPH). Initially developed at the second WSPH in Evian (France) in 1998 and subsequently updated in 2003 at the third WSPH in Venice (Italy) [1], this clinical classification system identifies five categories of disorders that cause $\mathrm{PH}$, with each group sharing similar hemodynamic, pathologic, and management features; PAH (Group 1); PH due to left heart disease (Group 2); PH due to chronic lung disease and/or hypoxia (Group 3); chronic thromboembolic PH (Group 4); and PH due to multifactorial mechanisms (Group 5).

The last significant changes to this classification system came at the fourth WSPH in Dana Point (USA) in 2008 [2] and have since been widely accepted in clinical and regulatory realms. It was not until the most recent fifth symposium in Nice (France) in 2013, however, that additional pediatric-specific categories of $\mathrm{PH}$ were added and previous ones, expanded, resulting in a new classification system that for the first time encompasses PH patients of all ages [ $3^{* *}$ ]. A separate pediatric classification system was discussed in Nice, but the $5^{\text {th }}$ WSPH Task Force on Pediatric PH ultimately decided that children and adolescents should retain the same $\mathrm{PH}$ classification when they transition from pediatric to adult care. The expanded classification system [Table 1] now includes independent categories of persistent pulmonary hypertension of the newborn (PPHN), which is a separate category due to its unique pathobiology and greater likelihood to resolve, congenital/acquired left heart inflow/ outflow tract obstruction, such as supravalvar mitral ring, cor triatriatum, and left ventricular outflow obstruction, and congenital cardiomyopathies (a new sub-type of Group 2). These, coupled with previous categories of PAH due to congenital heart disease, $\mathrm{PH}$ due to developmental lung diseases, and $\mathrm{PH}$ due to chronic hemolytic anemia such as sickle cell disease (SCD), better represent the spectrum of PH in children and adolescents. Of note, SCD and other chronic hemolytic anemias were moved to Group 5 given their disparate pathology, hemodynamics (including possibility of left ventricular diastolic dysfunction), and response to therapy. Finally, segmental PH, which incorporates patients with pulmonary atresia with ventricular septal defect, was added as a sub-type of Group 5 disease. The $5^{\text {th }}$ WSPH went on to emphasize the lifelong nature of PAH associated with congenital heart disease and also expanded its section on heritable PAH as new culprit gene mutations have been discovered in SMAD9 [4], caveolin-1 [5], and potassium channel KCNK3 [6*]. 


\section{Pathophysiology}

The pathophysiology of pulmonary vascular disease resulting in PH has routinely centered around pulmonary arteriopathy characterized by endothelial smooth muscle dysfunction, intimal thickening, and medial hypertrophy, with increased production of proliferative factors and decreased function of vasodilatory mediators [7,8]. Children and adolescents often have idiopathic PAH (IPAH) or congenital heart disease (CHD-PAH) [9-12] and in these cases this pathophysiology applies. Of additional importance in the pediatric population, however, is altered lung development and integrity, as is manifested in bronchopulmonary dysplasia (BPD), the most common chronic lung disease in children. This disease carries significant morbidity and mortality, especially when pulmonary pressures are elevated, and its impact on pediatric $\mathrm{PH}$ is substantial and worth further discussion.

The incidence of BPD has widely varied within the literature, but may be as high as $18 \%$ in infants weighing $<1,500 \mathrm{~g}[* 13]$. In infants with BPD, PH can occur in $~ 18-25 \%$ [13*, $14,15^{*}$ ]. In a recent, large, prospective, single-center study, 145 extremely low-birth-weight infants (birth weight less than 1000g) underwent screening echocardiography at a median age of 31 days of life and 6\% (9/145) were found to have PH, with an additional 12\% (17/145) developing signs of PH on subsequent echocardiograms, with a median age of diagnosis of 112 days of life [15*]. These studies have consistently shown that infants with more severe BPD are at greater risk of developing PH and have longer hospitalization times and higher mortality [Figure 1]. The mortality can be significant, with another retrospective study of patients with BPD and PH showing mortality rates as high as $36 \%$ at 6 months, $39 \%$ at 1 year, and $48 \%$ at 2 years after the diagnosis of PH [17]. While this study pre-dated PH-specific management therapies in BPD care, it highlights the significance of this disease in already vulnerable, premature infants.

Exploring BPD's pathophysiology has informed our understanding of pulmonary vascular biology in PH as was nicely described in a 2013 Current Opinion in Pediatrics review by Mourani and Abman [16**]. Briefly, impaired vascular growth and signaling, coupled with hypertensive vasculopathy and remodeling that occurs in the setting of lung and heart disease and chronic hypoxemia, provides the perfect substrate for the development of PH [16**]. The same group expanded its discussion of $\mathrm{PH}$ pathogenesis and management in an extensive review just recently published $\left[18^{* *}\right]$.

\section{Diagnosis}

Echocardiography continues to be the most reliable non-invasive screening tool in patients with risk factors or symptoms of PH [19**]. With a reliable tricuspid regurgitant jet velocity, one can calculate an estimated right ventricular systolic pressure that, in the absence of right ventricular outflow obstruction, approximates systolic pulmonary artery pressure. This remains an important tool for the diagnosis and surveillance of $\mathrm{PH}$ and carries a sensitivity of $\sim 89 \%$ [ $20 *]$. However, some patients with severe PH may have only trivial tricuspid regurgitation or poor imaging windows resulting in an incomplete Doppler pattern and underestimation of PH. Systolic interventricular septal flattening [21*], right ventricular and atrial enlargement, right ventricular hypertrophy or systolic dysfunction, and reversal of 
intracardiac shunt direction (if present) are other commonly known echocardiographic signs of $\mathrm{PH}$ and can help in the overall assessment of this disease. Other echocardiography-based markers, like the ratio of systolic to diastolic time [22], end-systolic right ventricular to left ventricular diameter ratio [23*], tricuspid plane annular excursion and eccentricity index $[21 *, 24 * *]$, and tissue Doppler indices [24**,25,26] have additionally been studied in recent years and may prove to be helpful going forward.

Non-invasive diagnosis and surveillance of $\mathrm{PH}$ now goes beyond the echocardiography lab and into the magnetic resonance imaging suite, where reliable anatomical and functional assessments of the right ventricle and pulmonary arteries can be performed. Although a challenging test in young patients with severe $\mathrm{PH}$ who are at high risk of problems with sedation, cardiac magnetic resonance (CMR) is increasingly becoming faster and more readily available. A recent study of 100 pediatric patients evaluated the prognostic capability of CMR in the assessment of $\mathrm{PH}$ and found that measurements of right ventricular ejection fraction and left ventricular stroke volume index were most strongly predictive of survival [27**]. Others have looked at wall shear stress in pulmonary arteries by phase contrast imaging in CMR and identified that it is decreased in patients with PAH relative to controls due to greater pulmonary artery dilatation with preserved systolic flow. This abnormal shear stress is believed to affect cellular mechanics, with altered inflammatory cytokine expression in more distal vessels, resulting in the medial hypertrophy and vascular pathology seen in $\mathrm{PH}[28 *$ ].

In those patients with suspected PH by echocardiography or CMR, right heart catheterization remains the definitive test to confirm PH (mean pulmonary artery pressure, mPAp, $>25 \mathrm{mmHg}$ ), identify PAH (PH plus a pulmonary capillary wedge pressure, PCWp, $<15 \mathrm{mmHg}$ and pulmonary vascular resistance, PVR, >3 Wood units), and perform acute vasoreactivity testing (AVT) with nitric oxide to guide management. AVT is routinely performed in patients with idiopathic $\mathrm{PAH}$ or heritable $\mathrm{PAH}$, and translating this practice to those with PAH due to congenital heart disease is often done as well. In children, calcium channel blockade (CCB) can be used as initial therapy in those who have a 'positive response' to AVT with nitric oxide, as defined by a decrease in mPAp $220 \%$ with a cardiac index that increases or remains unchanged and a ratio of pulmonary to systemic vascular resistance that decreases or remains unchanged [29]. In adults, a decrease in mPAp and PVR $>20 \%$ [30] or a decrease in the mPAp by $10 \mathrm{mmHg}$ to a value $<40 \mathrm{mmHg}$ with no decrease in cardiac output [31], define a positive response to AVT. The timing of changing a patient's management from the pediatric to adult definition of a positive response to AVT is unknown but is likely in mid-adolescence. Additional hemodynamic parameters that are prognostic in PH include the ratio of mPAp to mean systemic artery pressure, PVR to systemic vascular resistance, elevated right atrial pressure (primarily in adults), and indexed PVR $>20$ Wood units $\times \mathrm{m}^{2}\left[32^{* *}, 33,34\right]$, and the persistence of positive vasoreactivity testing, the latter of which has been shown to correlate with improved survival [11]. Recently, right ventricular stroke work (RVSW), or the product of mPAp and stroke volume and an assessment integrating contractility, afterload, and ventriculo-arterial coupling, has been shown to correlate with disease severity [35*]. At the $5^{\text {th }} \mathrm{WSPH}$, the Task Force on Diagnosis and 
Assessment nicely discussed the challenging questions surrounding hemodynamic definitions of $\mathrm{PH}$ and $\mathrm{PAH}[19 * *]$.

The six-minute walk distance and cardiopulmonary exercise test (CPET) remain less invasive and relatively inexpensive ways to follow patients between cardiac catheterizations and CMRs. Although less validated in the pediatric population, these tests can be reliably performed and are most helpful as a surveillance tool for an individual patient. Within the CPET, evaluation of markers other than peak VO2, such as the ventilatory efficiency slope (VE/VCO2 slope), have also been shown to correlate with functional capacity, disease severity, and outcomes [36*]. These tests have correlated with the World Health Organization (WHO) functional class assessment, which has been shown to contribute to a risk equation for PAH worsening and survival [37]. Often, simply identifying the patient's functional class goes a long way at helping with prognosis and management. A pediatricspecific functional class has been proposed, but not yet validated [38].

Finally, our diagnostic and surveillance capabilities are improving through the measurement of serum biomarkers such as brain natriuretic peptide (BNP) or the inactive N-terminal cleavage product of its pro-hormone (NT-proBNP) which, when elevated, have been associated with greater risk of death [39-43]. Additionally helpful is our growing ability to identify specific gene mutations such as those described previously. The genetic and epigenetic evaluation of patients with PH will increasingly become a part of our diagnostic and therapeutic approach to this disease and often informs our understanding of pathophysiology, as has been told in the story of bone morphogenetic protein receptor 2 (BMPR2). Mutations in this gene have been involved in multiple signaling pathways implicated in the development of PH. Our current understanding of BMPR2 regulation suggests that although $80 \%$ of familial PH is caused by a BMPR2 mutation, almost all forms of PH share abnormal BMPR2 signaling [44**].

\section{Management}

Inherent in studying any complex and rare pediatric disease is the lack of large clinical trials in children and the need to extrapolate data from adult studies or experiences. This is particularly the case in PH management given the breadth of disease phenotype and severity, coupled with an increasingly growing list of possible therapies, many with significant adverse effects.

At the fifth WSPH in Nice, a pediatric-specific treatment algorithm was proposed using expert opinion, and although most applicable to children with idiopathic $\mathrm{PAH}$, is worth reviewing further [Figure 2]. Basic therapies such as diuretics, oxygen, anticoagulation, and digoxin should be used on an individual basis and are often started during the diagnostic evaluation of a newly symptomatic patient. Right heart catheterization is routinely performed and should include AVT, with the initiation of CCB only in children with a positive AVT response, as described previously. For those with a negative response to AVT or failure to improve with $\mathrm{CCB}$, risk stratification should guide initial therapeutic choices. Severe right ventricular enlargement or dysfunction, pericardial effusion, significantly elevated or rising BNP or NT-proBNP, progression of symptoms, clinical evidence of right ventricular failure, poor functional class (WHO class III, symptoms with most activities, or 
WHO class IV, symptoms at rest), and syncope all suggest higher risk [TABLE 2], for which early combination therapy or IV therapy should be initiated [32**]. In those without these risk factors, single-agent oral therapy should be followed later by combination therapy if needed. Important in any of this management is frequent reassessment of these parameters and willingness to adjust therapies before right ventricular dysfunction or right heart failure ensues.

Initial single agent oral therapy should include either an endothelin receptor antagonist such as bosentan [45], ambrisentan [46], or macitentan [47*], the latter having been recently approved by the Food and Drug Administration (FDA). Perhaps more commonly started is a phosphodiesterase-5 inhibitor (PDE-5i) such as tadalafil [48] or sildenafil [49**]. Sildenafil came under particular scrutiny by the FDA during the summer of 2012 due to a (barely) clinically insignificant improvement in the pre-specified primary outcome, peak VO2 $(\mathrm{p}=$ $0.056)$, in the total aggregate of low- (10mg), medium- (10 to $40 \mathrm{mg}$ ), and high-dose (20 to $80 \mathrm{mg}$ ) administrations of sildenafil in the STARTS-1 trial [49**], coupled with an increased risk of mortality in the high-dose group with chronic use, who not surprisingly happened to have worse baseline hemodynamics before drug administration [50**]. In August 2012, the FDA went on to place a drug warning on (chronic) sildenafil use in children (ages 1 to 17 years) [51], inciting a collective gasp from parents of children on this medication and providers who had been prescribing it for years. Some providers interpreted this warning as a contraindication to administer the drug to children and stopped prescribing it altogether, so the FDA later went on to clarify their stance in March 2014, stating that "this (initial) recommendation was NOT intended to suggest that Revatio should never be used in children" [52**]. On further evaluation of these studies and recent review of pediatric $\mathrm{PH}$ registries, many $\mathrm{PH}$ providers are in agreement that low-dose sildenafil has a role in the management of this disease and that high-dose sildenafil should be avoided [53*,54*,55*]. Importantly, PDE-5i therapy should not be abruptly stopped as $\mathrm{PH}$ worsening and mortality may increase [54*].

In children who fail single-agent oral therapy or who have substantial risk factors for severe PH, combination therapy (early or add-on) or initiation of inhaled, subcutaneous, or intravenous prostacyclins may improve survival [FIGURE 3]. Inhaled prostacyclins (iloprost and treprostinil) have been shown to be a benefit as add-on therapy in low-risk patients [57,58] or as a diagnostic tool in AVT [59]. High-risk patients warrant initiation of intravenous epoprostenol or treprostinil $[59,60]$. Subcutaneous prostacyclin therapy is additionally carrying momentum [61]. Finally, those high-risk patients who are still declining despite prostanoids deserve consideration for atrial septostomy [62] or lung transplantation [63]. A descending aorta to left pulmonary artery shunt has been advocated by some groups [64] and may even be placed transcutaneously, but experience is limited [65].

Newer therapeutic agents and novel approaches include the recently FDA-approved soluble guanylate cyclase stimulator, riociguat, which increases cGMP production and vasodilation independent of the nitric oxide pathway [66]. This medication has been approved for adults with WHO Group $1 \mathrm{PAH}$ and patients with chronic thromboembolic pulmonary hypertension (CTEPH) who are not candidates for pulmonary endarterectomy or who have 
failed this therapy $\left[67^{*}\right]$. Riociguat causes bone dysplasia and growth plate injury in young, growing rats raising questions as to its use in pediatric patients [68]. Additionally, oral treprostinil was recently FDA-approved and is now commercially available [69*,70*]. As newer oral agents continue to emerge, the risks of chronic intravenous or subcutaneous prostanoid infusion may be avoided in some patients. Despite these advances, physicians remain challenged by the lack of evidence in deciding on drug therapy in children with $\mathrm{PH}$.

\section{Conclusion}

Much of what we know about PH in children and adolescents, including our understanding of its pathogenesis and therapy, continues to be largely extrapolated from adult patients and studies. While collaboration between centers and within multi-disciplinary teams is certainly improving, much is still to be known about the unique aspects of $\mathrm{PH}$ in pediatric patients.

Advancing our diagnostic and therapeutic understanding of $\mathrm{PH}$ comes through review of the recent literature, but additionally important is our development of patient registries as well as the ongoing participation of patients and providers in national and international organizations devoted to $\mathrm{PH}$ research. It is through this collective approach to this disease that we will continue to improve care of these complex patients.

\section{Acknowledgments}

Supported by the Jayden DeLuca Foundation; the Leah Bult Foundation; the Frederick and Margaret L Weyerhaeuser Foundation; UL1 TR000154: Colorado Clinical Translational Science Institute, National Center for Research Resources, and National Institutes of Health (NIH); HL-084923, HL114753.

\section{References}

1. Simonneau G, Galiè N, Rubin LJ, et al. Clinical classification of pulmonary hypertension. J Am Coll Cardiol. 2004; 43(12):S5-S12.

2. Simonneau G, Robbins IM, Beghetti M, et al. Updated clinical classification of pulmonary hypertension. J Am Coll Cardiol. 2009; 54:S43-54. [PubMed: 19555858]

3**. Simonneau G, Gatzoulis MA, Adatia I, et al. Updated clinical classification of pulmonary hypertension. J Am Coll Cardiol. 2013; 62:D34-41. [PubMed: 24355639] [Key paper from the $5^{\text {th }}$ WSPH outlining the most recent changes in the classification of PH, the first iteration of this system to identify and highlight pediatric-specific causes of PH.]

4. Nasim MT, Ogo T, Ahmed M, et al. Molecular genetic characterization of SMAD signaling molecules in pulmonary arterial hypertension. Hum Mutat. 2011; 32(12):1385-9. [PubMed: 21898662]

5. Austin ED, Ma L, LeDuc C, et al. Whole exome sequencing to identify a novel gene (Caveolin-1) associated with human pulmonary arterial hypertension. Circ Cardiovasc Genet. 2012; 5:336-343. [PubMed: 22474227]

6*. Ma L, Roman-Campos D, Austin ED, et al. A novel channelopathy in pulmonary arterial hypertension. N Engl J Med. 2013; 369(4):351-61. [PubMed: 23883380] [Study that describes the identification of a new gene that, when mutated, results in a potassium channelopathy involved in familial and idiopathic PAH.]

7. Humbert M, Morrell NW, Archer SL, et al. Cellular and molecular pathobiology of pulmonary arterial hypertension. J Am Coll Cardiol. 2004; 43(12):S13-S24.

8. Rabinovitch M. Pathobiology of pulmonary hypertension. Annu Rev Pathol Mech Dis. 2007; 2(1): 369-99.

Curr Opin Pediatr. Author manuscript; available in PMC 2015 October 01. 
9. Fraisse A, Jaïs X, Schleich J-M, et al. Characteristics and prospective 2-year follow-up of children with pulmonary arterial hypertension in France. Archives of Cardiovascular Diseases. Feb. 2010; 103(2):66-74. [PubMed: 20226425]

10. Barst RJ, Ertel SI, Beghetti M, Ivy DD. Pulmonary arterial hypertension: A comparison between children and adults. Eur Respir J. 2011; 37(3):665-77. [PubMed: 21357924]

11. Barst RJ, McGoon MD, Elliott CG, et al. Survival in childhood pulmonary arterial hypertension: Insights from the registry to evaluate early and long-term pulmonary arterial hypertension disease management. Circulation. 2012; 125(1):113-22. [PubMed: 22086881]

12. Berger RM, Beghetti M, Humpl T, et al. Clinical features of paediatric pulmonary hypertension: a registry study. Lancet. 2012; 379(9815):537-46. [PubMed: 22240409]

13*. Ali Z, Schmidt P, Dodd J, Jeppesen DL. Predictors of bronchopulmonary dysplasia and pulmonary hypertension in newborn children. Dan Med J. 2013; 60(8):A4688-8. [PubMed: 23905570] [Retrospective study finding an $18 \%$ incidence of PH in BPD. Some risk factors for BPD and PH were identified.]

14. An HS, Bae EJ, Kim GB, et al. Pulmonary hypertension in preterm infants with bronchopulmonary dysplasia. Korean Circ J. 2010; 40(3):131-6. [PubMed: 20339498]

$15^{*}$. Bhat R, Salas AA, Foster C, et al. Prospective analysis of pulmonary hypertension in extremely low birth weight infants. J Pediatr. 2012; 129(3):e682-9. [Prospective study evaluating the association of BPD with PH, reporting that screening echocardiography at 4-6 weeks identifies only one third of patients who ultimately develop PH by discharge, suggesting the need for repeat evaluations.]

16**. Mourani PM, Abman SH. Pulmonary vascular disease in bronchopulmonary dysplasia. Curr Opin Pediatr. Jun. 2013; 25(3):329-37. [PubMed: 23615175] [Review outlining the pathophysiology, epidemiology, and treatment of $\mathrm{PH}$ in the setting of BPD.]

17. Khemani E, McElhinney DB, Rhein L, et al. Pulmonary artery hypertension in formerly premature infants with bronchopulmonary dysplasia: Clinical features and outcomes in the surfactant era. $\mathrm{J}$ Pediatr. 2007; 120(6):1260-9.

$18 * *$. Baker CD, Abman SH, Mourani PM. Pulmonary hypertension in preterm infants with bronchopulmonary dysplasia. Pediatric Allergy, Immunology, and Pulmonology. 2014; 27(1):816. [Review highlighting our recent understanding of pulmonary vascular disease in BPD associated with PH.]

19**. Hoeper MM, Bogaard HJ, Condliffe R, et al. Definitions and diagnosis of pulmonary hypertension. J Am Coll Cardiol. 2013; 62(25):D42-D50. [PubMed: 24355641] [Important paper from the $5^{\text {th }}$ WSPH discussing the challenges in accurately diagnosing $\mathrm{PH}$ and PAH.]

20*. Lafitte S, Pillois X, Reant P, et al. Estimation of pulmonary pressures and diagnosis of pulmonary hypertension by Doppler echocardiography: A retrospective comparison of routine echocardiography and invasive hemodynamics. J Am Soc of Echocardiogr. 2013; 26(5):457-63. [PubMed: 23510536] [Retrospective study confirming the validity and utility of Doppler echocardiography in diagnosing and following PH.]

21*. Haddad F, Guihaire J, Skhiri M, et al. Septal curvature is a marker of hemodynamic, anatomical, and electromechanical ventricular interdependence in patients with pulmonary arterial hypertension. Echocardiography. 2013; 00:1-9. [Echo-derived eccentricity index and interventricular septal curvature are markers of RV size and systolic function.]

22. Alkon J, Humpl T, Manlhiot C, et al. Usefulness of the right ventricular systolic to diastolic duration ratio to predict functional capacity and survival in children with pulmonary arterial hypertension. Am J Cardiol. 2010; 106(3):430-6. [PubMed: 20643259]

23*. Jone P-N, Hinzman J, Wagner BD, et al. Right ventricular to left ventricular diameter ratio at endsystole in evaluating outcomes in children with pulmonary hypertension. J Am Soc of Echocardiogr. 2014; 27(2):172-8. [PubMed: 24325962] [Echo study showing that an endsystolic RV to LV ratio >1 correlates with hemodynamic measures of $\mathrm{PH}$.]

24**. Kassem E, Humpl T, Friedberg MK. Prognostic significance of 2-dimensional, M- mode, and Doppler echo indices of right ventricular function in children with pulmonary arterial hypertension. Am Heart J. 2013; 165(6):1024-31. [PubMed: 23708176] [Restrospective echo study evaluating several methods of RV function as they correlate to PAH transplant and 
mortality in children. Echo-based RV function had previously primarily been evaluated only in adults.]

25. Lammers AE, Haworth SG, Riley G, et al. Value of tissue Doppler echocardiography in children with pulmonary hypertension. J Am Soc of Echocardiogr. 2012; 25(5):504-10. [PubMed: 22365880]

26. Takatsuki S, Nakayama T, Jone P-N, et al. Tissue Doppler imaging predicts adverse outcome in children with idiopathic pulmonary arterial hypertension. The J Pediatr. 2012; 161(6):1126-31.

$27^{* *}$. Moledina S, Pandya B, Bartsota M, et al. Prognostic significance of cardiac magnetic resonance imaging in children with pulmonary hypertension. Circ Cardiovasc Imaging. 2013; 6:407-414. [PubMed: 23572488] [First study to show that cardiac MRI parameters correlate with clinical status and prognosis in pediatric $\mathrm{PH}$.

28*. Truong U, Fonseca B, Dunning J, et al. Wall shear stress measured by phase contrast cardiovascular magnetic resonance in children and adolescents with pulmonary arterial hypertension. J Cardiovasc Magn Reson. 2013; 15(1):81. [PubMed: 24034144] [Cardiac MRI was used to identify decreased wall sheer stress in PAH patients with large pulmonary arteries, which correlates with more vascular stiffness and altered cellular regulation, presumably resulting in the vascular changes seen in $\mathrm{PH}$.]

29. Barst RJ. Pharmacologically induced pulmonary vasodilatation in children and young adults with primary pulmonary hypertension. Chest. 1986; 89:497-503. [PubMed: 2869919]

30. Rich S, Kaufmann E, Levy PS. The effect of high doses of calcium-channel blockers on survival in primary pulmonary hypertension. N Engl J Med. 1992; 327:76-81. [PubMed: 1603139]

31. Sitbon O, Humbert M, Jaïs X, et al. Long-term response to calcium channel blockers in idiopathic pulmonary arterial hypertension. Circulation. 2005; 111(23):3105-11. [PubMed: 15939821]

32**. Ivy DD, Abman SH, Barst RJ, et al. Pediatric pulmonary hypertension. J Am Coll Cardiol. 2013; 62(25):D117-26. [PubMed: 24355636] [Key paper from the $5^{\text {th }}$ WSPH reviewing new developments in pediatric PH as discussed by the Task Force on Pediatric PH.]

33. Ivy DD, Rosenzweig EB, Lemarie JC, et al. Long-term outcomes in children with pulmonary arterial hypertension treated with bosentan in real-world clinical settings. Am J Cardiol. 2010; 106:1332-8. [PubMed: 21029834]

34. Douwes JM, van Loon RLE, Hoendermis ES, et al. Acute pulmonary vasodilator response in paediatric and adult pulmonary arterial hypertension: Occurrence and prognostic value when comparing three response criteria. Eur Heart J. 2011; 32(24):3137-46. [PubMed: 21893489]

35*. DiMaria MV, Younoszai A, Mertens L, et al. RV stroke work in children with pulmonary arterial hypertension: Estimation based on invasive haemodynamic assessment and correlation with outcomes. Heart. 2014:1-6. [PubMed: 24319086] [Decreased right ventricular stroke work, which is calculated using mean pulmonary artery pressure and stroke volume and is a marker of RV function, correlates with increased severity of PH.]

36*. Rausch CM, Taylor AL, Ross H, et al. Ventilatory efficiency slope correlates with functional capacity, outcomes, and disease severity in pediatric patients with pulmonary hypertension. Int $\mathrm{J}$ Cardiol. 2013; 169(6):445-8. [PubMed: 24144928] [VE/VCO2 slope, a marker of submaximal exercise capacity, correlates with noninvasive and invasive markers of PH severity.]

37. Benza RL, Miller DP, Gomberg-Maitland M, et al. Predicting survival in pulmonary arterial hypertension: insights from the Registry to Evaluate Early and Long-Term Pulmonary Arterial Hypertension Disease Management (REVEAL). Circulation. 2010; 122(2):164-72. [PubMed: 20585012]

38. Lammers A, del Cerro M, Freudenthal A, et al. Functional classification of pulmonary hypertension in children: report from the PVRI pediatric taskforce. Panama. Pulm Circ 2011. $2011 ; 1(2): 280$.

39. Andreassen AK, Wergeland R, Simonsen S, et al. N-terminal pro-B-type natriuretic peptide as an indicator of disease severity in a heterogeneous group of patients with chronic precapillary pulmonary hypertension. Am J Cardiol. 2006; 98(4):525-9. [PubMed: 16893710]

40. Fijalkowska A, Kurzyna M, Torbicki A, et al. Serum N-terminal brain natriuretic peptide as a prognostic parameter in patients with pulmonary hypertension. Chest. 2006; 129(5):1313-21. [PubMed: 16685024] 
41. Van Albada ME, Loot FG, Fokkema R, et al. Biological serum markers in the management of pediatric pulmonary arterial hypertension. Pediatr Res. 2008; 63(3):321-7. [PubMed: 18287971]

42. Bernus A, Wagner BD, Accurso F. Brain natriuretic peptide levels in managing pediatric patients with pulmonary arterial hypertension. Chest. 2009; 135(3):745-51. [PubMed: 18849405]

43. Lammers AE, Hislop AA, Haworth SG. Prognostic value of B-type natriuretic peptide in children with pulmonary hypertension. Int J Cardiol. 2009; 135(1):21-6. [PubMed: 18599134]

44**. West J, Austin E, Fessel JP, et al. Rescuing the BMPR2 signaling axis in pulmonary arterial hypertension. Drug Discov Today. 2014 in press. [Study that explores the therapeutic possibilities of targeting the BMPR-2 signaling pathway, which is impaired in PAH.]

45. Hislop AA, Moledina S, Foster H, et al. Long-term efficacy of bosentan in treatment of pulmonary arterial hypertension in children. Eur Respir J. 2011; 38(1):70-7. [PubMed: 21177841]

46. Takatsuki S, Rosenzweig EB, Zuckerman W, et al. Clinical safety, pharmacokinetics, and efficacy of ambrisentan therapy in children with pulmonary arterial hypertension. Pediatr Pulmonol. 2012; 48(1):27-34. [PubMed: 22511577]

47*. Pulido T, Adzerikho I, Channick RN, et al. Macitentan and morbidity and mortality in pulmonary arterial hypertension. N Engl J Med. 2013; 369(9):809-18. [PubMed: 23984728] [Randomized, placebo-controlled trial showing improved morbidity and mortality in PAH patients using macitentan, a new endothelin recepor antagonist, as single or add-on therapy.]

48. Takatsuki S, Calderbank M, Ivy DD. Initial experience with tadalafil in pediatric pulmonary arterial hypertension. Pediatr Cardiol. 2012; 33(5):683-8. [PubMed: 22402804]

49**. Barst RJ, Ivy DD, Gaitan G, et al. A randomized, double-blind, placebo-controlled, dose-ranging study of oral sildenafil citrate in treatment-naive children with pulmonary arterial hypertension. Circulation. 2012; 125(2):324-34. [PubMed: 22128226] [Important, randomized, placebocontrolled trial of 16 weeks of sildenafil monotherapy in PAH, that showed improved peak VO2 and functional status in patients on medium and high-dose sildenafil.]

50**. Barst RJ, Beghetti M, Pulido T, et al. STARTS-2: Long-term survival with oral sildenafil monotherapy in treatment-naïve pediatric pulmonary arterial hypertension. Circulation. 2014; 129:1914-23. [PubMed: 24637559] [Extension of STARTS-1 trial that showed a benefit of sildenafil on functional status at all doses with a slightly increased risk of mortality in patients on chronically higher doses. Mortality data while this study was ongoing led to the 2013 FDA warning on sildenafil use in children.]

51. Commissioner, OOT. Safety Alerts for Human Medical Products - Revatio (sildenafil): Drug Safety Communication - Recommendation Against Use in Children. http:/www.fda.gov/Drugs/ DrugSafety/ucm317123.htm

52**. Commissioner, OOT. Safety Alerts for Human Medical Products - Revatio (sildenafil): Drug Safety Communication - FDA Clarifies Warning About Pediatric Use for Pulmonary Arterial Hypertension. http://www.fda.gov/Drugs/DrugSafety/ucm390876.htm. [FDA clarification of its previous warning on the use of sildenafil in children, stating that lower doses of the medication may be safe in children.]

53*. Roldan T, Deiros L, Romero JA, et al. Safety and tolerability of targeted therapies for pulmonary hypertension in children. Pediatr Cardiol. 2013; 35(3):490-8. [PubMed: 24141893]

[Retrospective analysis of 63 pediatric patients on sildenafil, bosentan, or combination therapy, showing significant therapeutic efficacy with minimal severe adverse events.]

54*. Abman SH, Kinsella JP, Rosenzweig EB, et al. Implications of the U.S. Food and Drug Administration warning against the use of sildenafil for the treatment of pediatric pulmonary hypertension. Am J Respir Crit Care Med. 2013; 187(6):572-5. [PubMed: 23220921] [Response to 2012 FDA warning with review of pertinent literature and recommendations on reasonable use of sildenafil.]

55*. Douwes JM, Roofthooft MTR, Van Loon RLE, et al. Sildenafil add-on therapy in paediatric pulmonary arterial hypertension, experiences of a national referral centre. Heart. 2014; 100:224230. [PubMed: 24390161] [Small but important (given its timing) study of add-on sildenafil therapy in pediatric patients failing on therapy with bosentan, showing improved WHO functional class and six-minute walk testing.]

56**. Zijlstra WM, Douwes JM, Rosenzweig EB, et al. Survival differences in pediatric pulmonary arterial hypertension: Clues to a better understanding of outcome and optimal treatment 
strategies. J Am Coll Cardiol. 2014 in press. [Comparison of mortality differences in three different PAH centers, finding that referral base and disease severity affect survival.

Additionally, showed that combination therapy improves survival over monotherapy.]

57. Limsuwan A, Wanitkul S, Khosithset A, et al. Aerosolized iloprost for postoperative pulmonary hypertensive crisis in children with congenital heart disease. Int J of Cardiol. 2008; 129(3):333-8. [PubMed: 18096256]

58. Krishnan U, Takatsuki S, Ivy DD, et al. Effectiveness and safety of inhaled treprostinil for the treatment of pulmonary arterial hypertension in children. Am J Cardiol. 2012; 110(11):1704-9. [PubMed: 22917554]

59. Takatsuki S, Parker DK, Doran AK, et al. Acute pulmonary vasodilator testing with inhaled treprostinil in children with pulmonary arterial hypertension. Pediatr Cardiol. 2012; 34(4):100612. [PubMed: 23184020]

60. Siehr SL, Dunbar Ivy D, Miller-Reed K, et al. Children with pulmonary arterial hypertension and prostanoid therapy: Long-term hemodynamics. J Heart Lung Transplant. 2013; 32(5):546-52. [PubMed: 23453572]

61. Levy M, Celermajer DS, Bourges-Petit E, et al. Add-on therapy with subcutaneous treprostinil for refractory pediatric pulmonary hypertension. J Pediatr. 2011; 158(4):584-8. [PubMed: 21035821]

62. Sandoval J, Gaspar J, Pulido T, et al. Graded balloon dilation atrial septostomy in severe primary pulmonary hypertension. J Am Coll Cardiol. 1998; 32(2):297-304. [PubMed: 9708453]

63. Goldstein BS, Sweet SC, Mao J, et al. Lung transplantation in children with idiopathic pulmonary arterial hypertension: An 18-year experience. J Heart Lung Transplant. 2011; 30(10):1148-52. [PubMed: 21620736]

64. Baruteau A-E, Serraf A, Lévy M, et al. Potts shunt in children with idiopathic pulmonary arterial hypertension: Long-term results. Ann Thorac Surg. 2012; 94(3):817-24. [PubMed: 22704329]

65. Esch JJ, Shah PB, Cockrill BA, et al. Transcatheter Potts shunt creation in patients with severe pulmonary arterial hypertension: Initial clinical experience. J Heart Lung Transplant. 2013; 32:381-387. [PubMed: 23415728]

66. Ghofrani HA, Hoeper MM, Halank M, et al. Riociguat for chronic thromboembolic pulmonary hypertension and pulmonary arterial hypertension: A phase II study. Eur Respir J. 2010; 36(4): 792-9. [PubMed: 20530034]

67*. Ghofrani H-A, D'Armini AM, Grimminger F, et al. Riociguat for the treatment of chronic thromboembolic pulmonary hypertension. N Engl J Med. 2013; 369(4):319-29. [PubMed: 23883377] [Randomized controlled trial providing the data to support the 2013 FDA approval of macitentan for use in patients with PAH and/or chronic thromboembolic PH (CTEPH) not amenable to pulmonary thromboendarterectomy.]

68. CDER F. FDA draft briefing document for the Cardiovascular and Renal Drugs Advisory Committee (CRDAC). 2013:1-315.

69*. Jing ZC, Parikh K, Pulido T, et al. Efficacy and Safety of Oral Treprostinil Monotherapy for the Treatment of Pulmonary Arterial Hypertension. Circulation. 2013; 127:624-633. [PubMed: 23307827] [Multicenter, international, double-blinded, randomized, placebo-controlled study evaluating oral treprostinil as monotherapy, showing improved functional capacity. Led to FDA approval of the drug despite the negative study of oral treprostinil as add-on therapy, \#70, below.]

70*. Tapson VF, Jing ZC, Xu K-F, et al. Oral treprostinil for the treatment of pulmonary arterial hypertension in patients receiving background endothelin receptor antagonist and phosphodiesterase type 5 inhibitor therapy (the FREEDOM-C2 study): A randomized controlled trial. Chest. 2013; 144(3):952-8. [PubMed: 23669822] [Double-blinded, randomized, placebocontrolled trial evaluating oral treprostinil as add on therapy in patients on endothelin receptor antagonists, showing no significant improvement in endpoints and common but well-tolerated side effects.] 


\section{Key Points}

- The WHO classification of pulmonary hypertension (PH) was amended in 2013 and now includes improved identification of pediatric-specific characteristics of the disease.

- The presence of PH increases morbidity and mortality in patients with bronchopulmonary dysplasia and relates to impaired vascular growth and signaling, coupled with hypertensive vasculopathy and remodeling stimulated by chronic hypoxemia.

- While echocardiography and cardiac catheterization remain key diagnostic tools in $\mathrm{PH}$, novel uses of magnetic resonance imaging and new targets in the areas of exercise physiology, biomarkers, and genetics are enhancing our diagnostic and prognostic abilities.

- Although $80 \%$ of familial pulmonary arterial hypertension (PAH) is caused by mutations of the bone morphogenetic protein receptor 2 (BMPR2), almost all forms of PH share abnormal BMPR2 signaling.

- Within the past year, three new drugs were approved by the FDA to treat PAH in adults and will encourage ongoing discussion about use in children. Additionally, the chronic use of sildenafil in pediatric patients came under scrutiny but continues to be a mainstay of therapy at lower doses. 


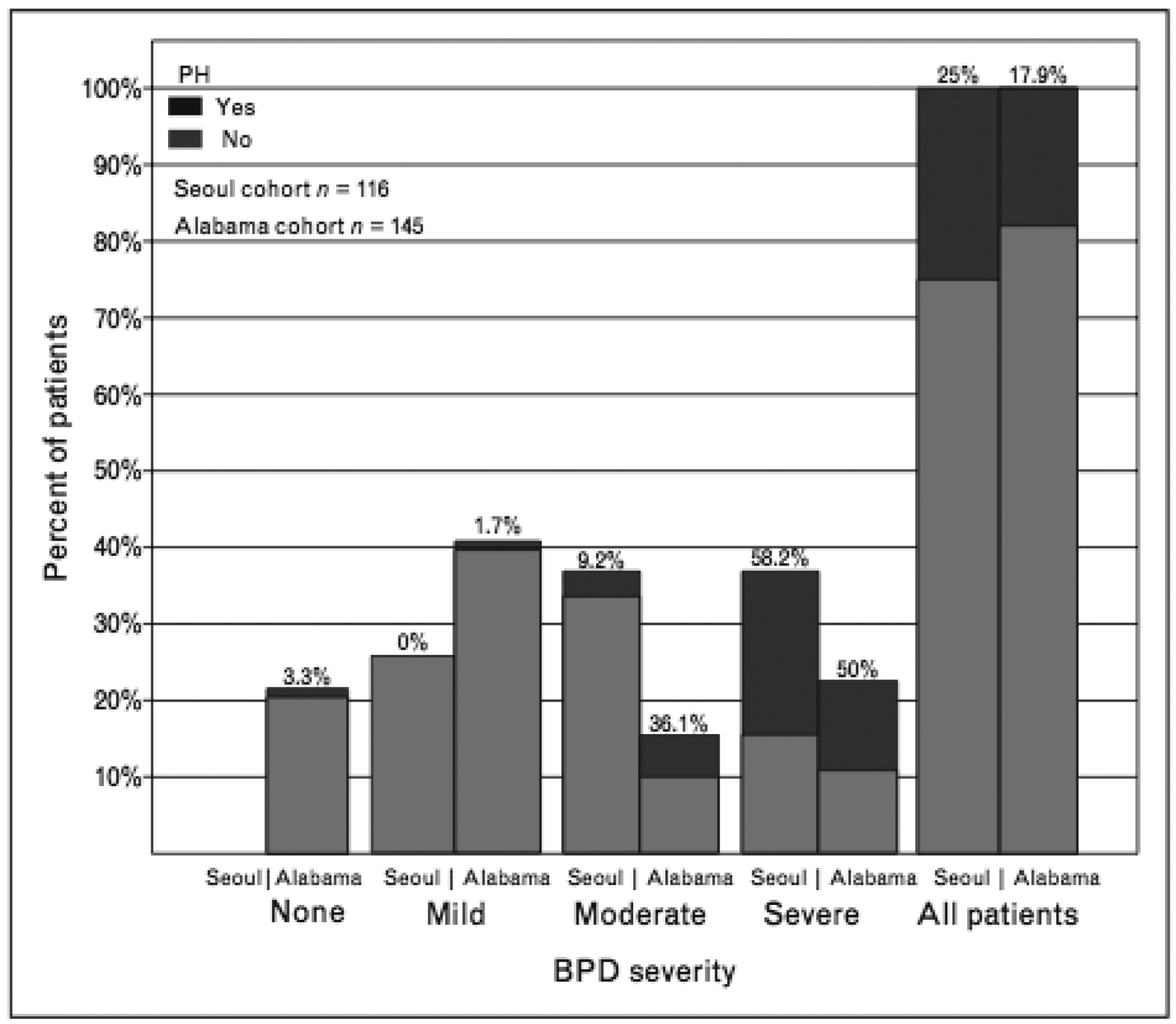

Figure 1.

Incidence of Pulmonary Hypertension According to Severity of Bronchopulmonary Dysplasia Severity Incidence of pulmonary hypertension increases with severity of bronchopulmonary dysplasia, as described in two recent studies. Reprinted with permission, Mourani, et al. Curr Opin Pediatr 2013; 25:329-337 [16**]. 


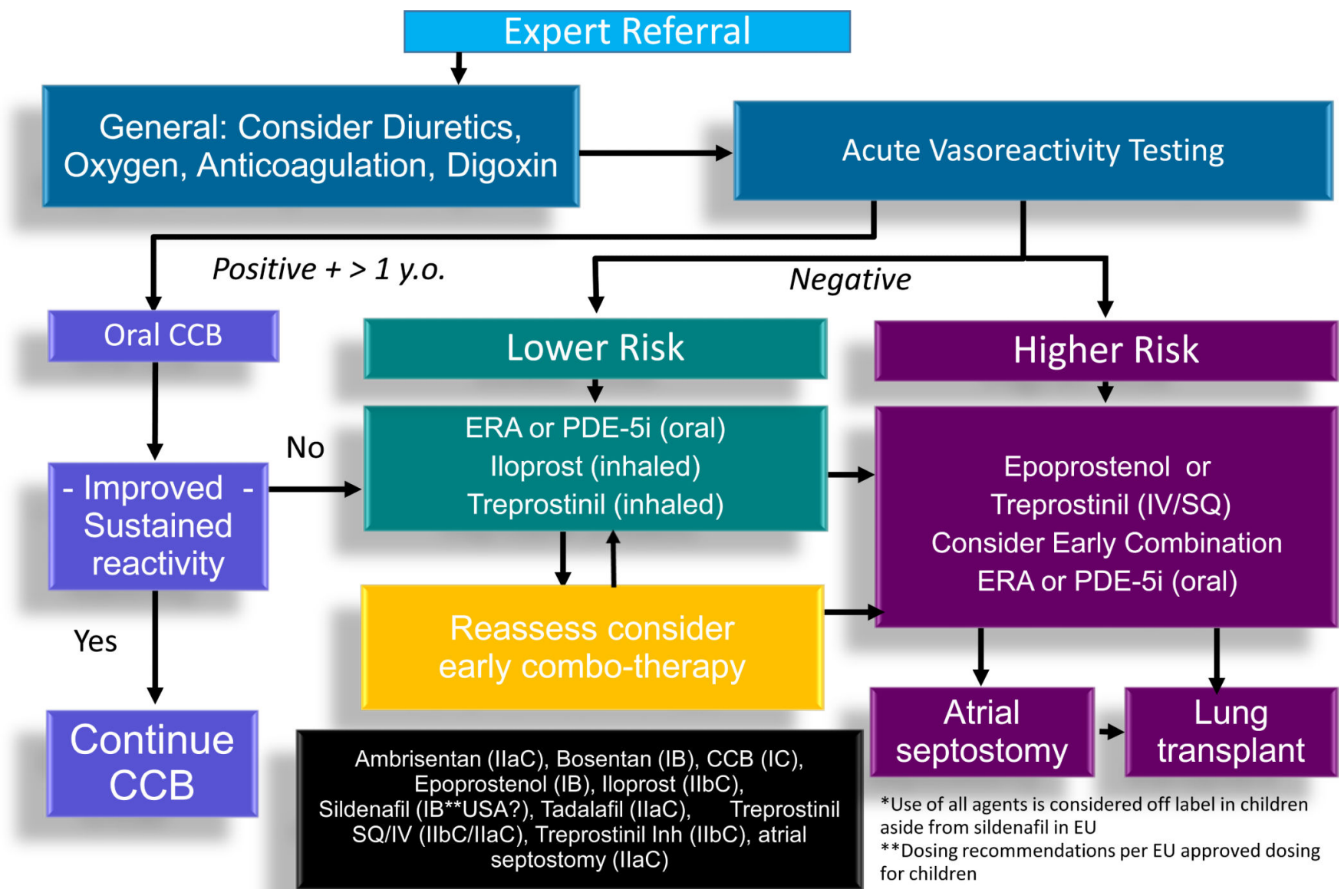

Figure 2.

Proposed Treatment Algorithm for Idiopathic Pulmonary Arterial Hypertension

Treatment algorithm proposed in the management of pediatric patients with idiopathic or heritable pulmonary arterial hypertension. May be translatable to other patients with pulmonary hypertension. $\mathrm{CCB}=$ calcium channel blocker; ERA = endothelin receptor antagonist; PDE-5i = phosphodiesterase 5 inhibitor. Reprinted with permission, Ivy, et al. J Am Coll Cardiol 2013;62:D117-26 [32**]. 


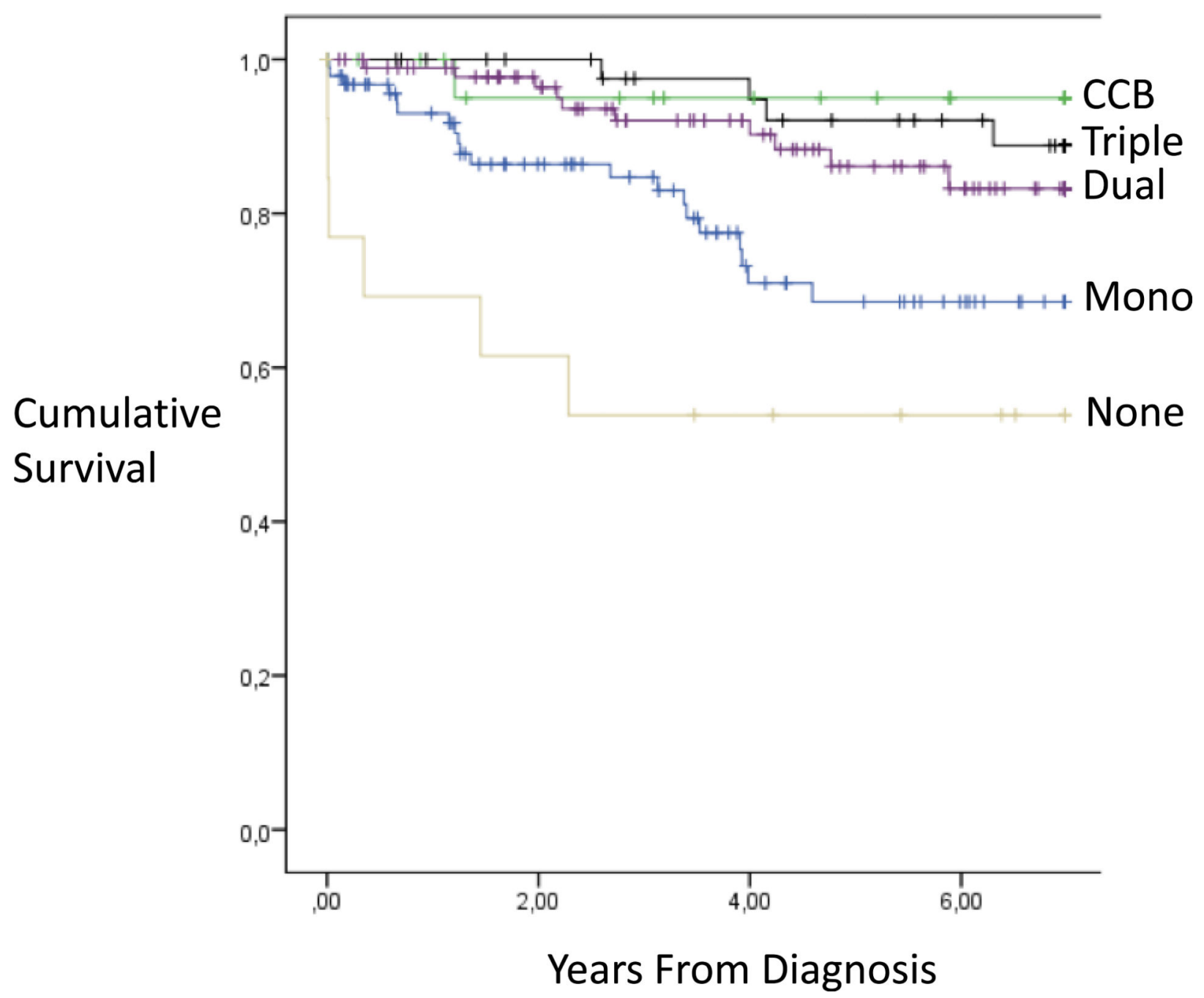

Figure 3.

Survival According to Extent of Pulmonary Hypertension Therapy

Survival improves on combination therapy for pulmonary hypertension over mono- therapy. $\mathrm{CCB}=$ calcium channel blocker. Adapted with permission, Zijlstra et al. J Am Coll Cardiol 2014 ; in press [56**]. 


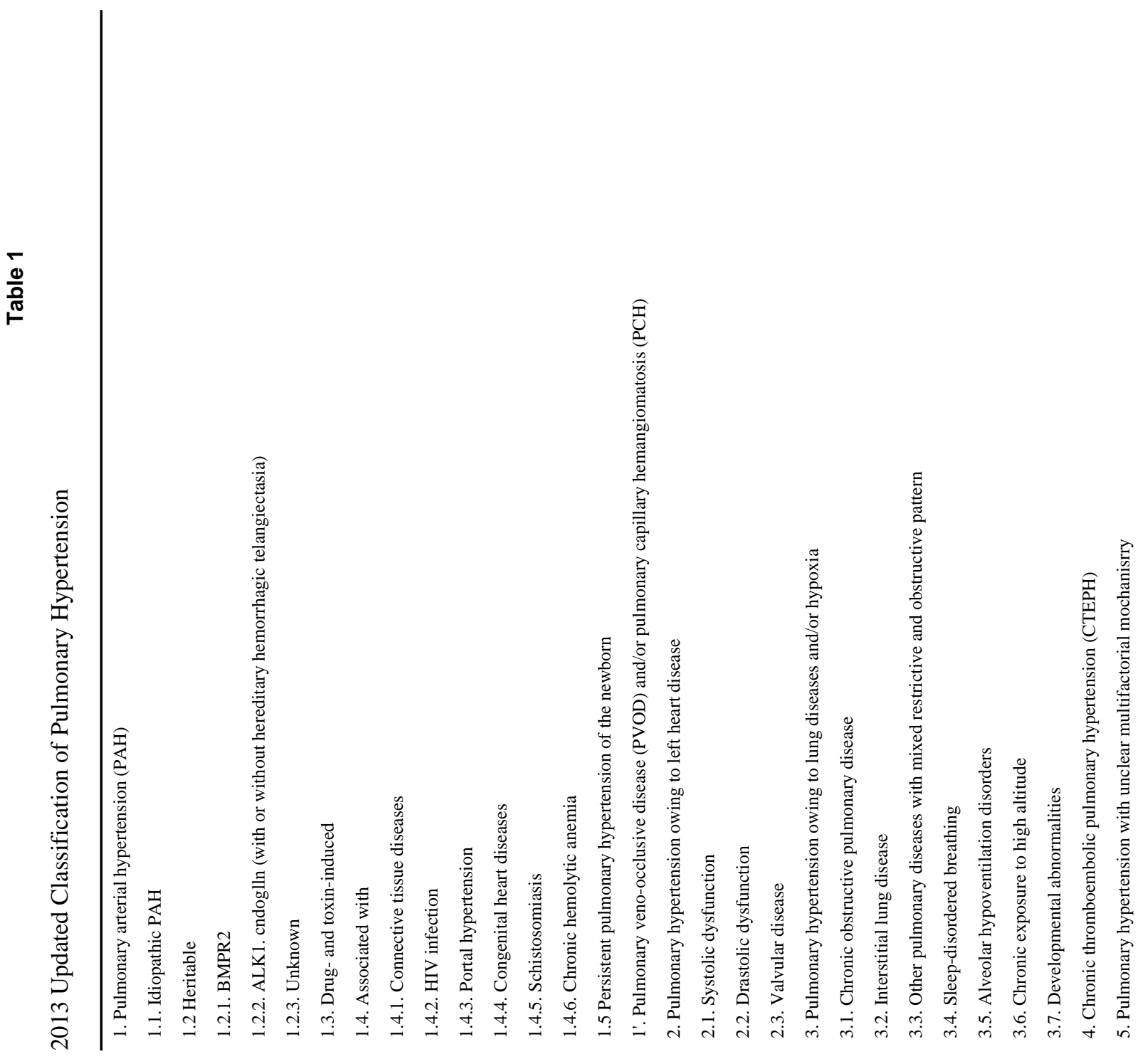




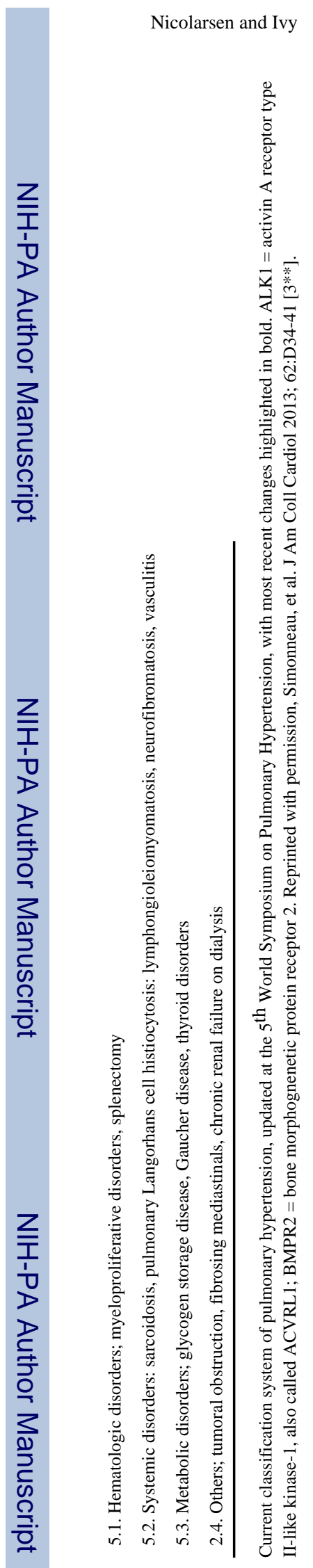

Curr Opin Pediatr. Author manuscript; available in PMC 2015 October 01. 


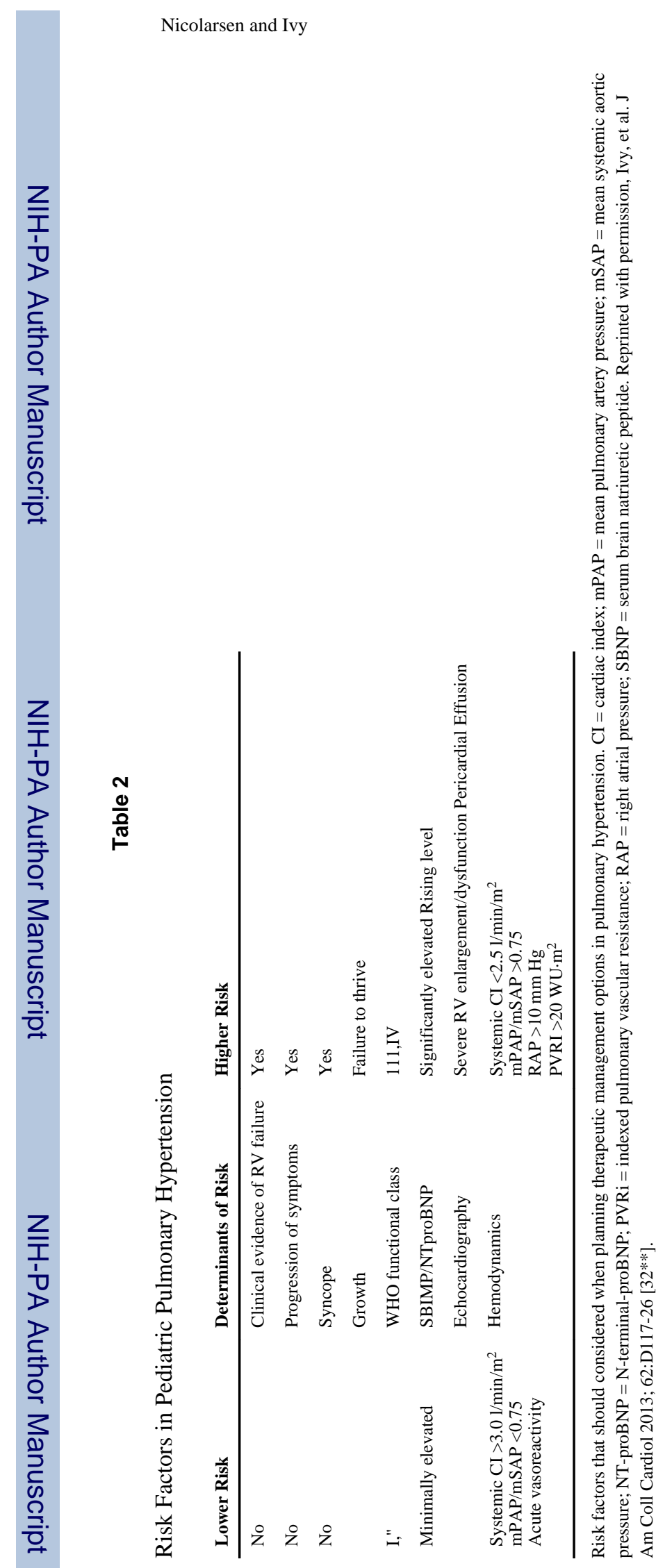

Curr Opin Pediatr. Author manuscript; available in PMC 2015 October 01. 